\title{
Outcome of Holiday and Nonholiday Admission Patients with Acute Peptic Ulcer Bleeding: A Real-World Report from Southern Taiwan
}

\author{
Tsung-Chin Wu, Seng-Kee Chuah, Kuo-Chin Chang, Cheng-Kun Wu, Chung-Huang Kuo, \\ Keng-Liang Wu, Yi-Chun Chiu, Tsung-Hui Hu, and Wei-Chen Tai
}

\begin{abstract}
Division of Hepatogastroenterology, Department of Internal Medicine, Kaohsiung Chang Gung Memorial Hospital and Chang Gung University College of Medicine, 123 Ta-Pei Road, Niaosung Hsiang, Kaohsiung City 833, Taiwan
\end{abstract}

Correspondence should be addressed to Wei-Chen Tai; luketai1019@gmail.com

Received 9 May 2014; Accepted 18 June 2014; Published 1 July 2014

Academic Editor: Deng-Chyang Wu

Copyright (C) 2014 Tsung-Chin Wu et al. This is an open access article distributed under the Creative Commons Attribution License, which permits unrestricted use, distribution, and reproduction in any medium, provided the original work is properly cited.

Background. Recent findings suggest that patients admitted on the weekend with peptic ulcer bleeding might be at increased risk of adverse outcomes. However, other reports found that there was no "holiday effect." The purpose of this study was to determine if these findings hold true for a real-life Taiwanese medical gastroenterology practice. Materials and Methods. We reviewed the medical files of hospital admissions for patients with peptic ulcer bleeding who received initial endoscopic hemostasis between January 2009 and March 2011. A total of 744 patients were enrolled (nonholiday group, $n=615$; holiday group, $n=129$ ) after applying strict exclusion criteria. Holidays were defined as weekends and national holidays in Taiwan. Results. Our results showed that there was no significant difference in baseline characteristics between the two groups. We also observed that, compared to the nonholiday group, patients in the holiday group received earlier endoscopy treatment (12.20 hours versus 16.68 hours, $P=0.005$ ), needed less transfused blood ( 4.8 units versus 6.6 units, $P=0.02$ ), shifted from intravenous to oral proton-pump inhibitors (PPIs) more quickly (5.3 days versus 6.9 days, $P=0.05$ ), and had shorter hospital stays (13.05 days versus 17.36 days, $P=0.005$ ). In the holiday and nonholiday groups, the rebleeding rates were $17.8 \%$ and $23.41 \%(P=0.167)$, the mortality rates were $11.63 \%$ versus $13.66 \%(P=0.537)$, and surgery was required in $2.11 \%$ versus $4.66 \%(P=0.093)$, respectively. Conclusions. Patients who presented with peptic ulcer bleeding on holidays did not experience delayed endoscopy or increased adverse outcomes. In fact, patients who received endoscopic hemostasis on the holiday had shorter waiting times, needed less transfused blood, switched to oral PPIs quicker, and experienced shorter hospital stays.

\section{Introduction}

Peptic ulcer bleeding is a common cause of hospitalization, and mortality remains at $6-8 \%$ despite advances in both pharmacologic and endoscopic therapies [1,2]. Reports regarding outcomes for different management regimens for peptic ulcer bleeding patients during holidays are inconsistent. Some described increased adverse outcomes on holidays $[3,4]$ while others did not $[5,6]$.

It is well documented that the risk for recurrent bleeding is increased in patients with high-risk peptic ulcers after initial endoscopic hemostasis, although it can control bleeding and reduce the rebleeding, morbidity, and mortality rates
$[7,8]$. Theoretically, the possibility of greater risk on holidays is due to potential lower staffing levels, less senior staff, cross-cover of clinical specialties, and a lower likelihood that invasive procedures, such as endoscopy, will be performed on holidays. Peptic ulcer bleeding is a common medical emergency in Taiwan that challenges both gastroenterologis ts and general surgeons. The purpose of this study was to determine whether the holiday effect occurred in our hospital. We analyzed the outcomes of patients with peptic ulcer bleeding who presented on holidays compared to those admitted on nonholidays. The endpoints were rebleeding, need for surgery, and mortality. 


\section{Materials and Methods}

2.1. Study Design. Between January 2009 and March 2011, we performed 37,019 esophagogastroduodenoscopy studies in our endoscopic center. Among them, 1,051 patients underwent endoscopic hemostasis for confirmed gastric and duodenal ulcer bleeding. All subjects received the intravenous proton-pump inhibitors (PPIs). After the medical records of these 1,051 patients were reviewed, we excluded 307 patients with malignant ulcers and nonulcerative bleeding (e.g., angiodysplasia, Mallory-Weiss tear), subjects lost to followup before 30 days (except those who died), and patients with incomplete chart records. Eventually, we included 744 patients in this study. We divided these patients into holiday $(n=129)$ and nonholiday groups $(n=615)$ (Figure 1$)$. Gastric or duodenal ulcers bleeding was diagnosed by the gastroscopy (GIF-Q260; Olympus Optical Co., Ltd., Tokyo, Japan) and clinical signs of hematemesis, coffee ground vomitus, hematochezia, or melena. The time from admission to endoscopic treatment was measured, and the bleeding source was identified. Patients' statuses were stratified according to the Rockall score system [9]. All of our patients received endoscopic interventions within 24 hours of arriving at the emergency room, and endoscopic hemostasis interventions were performed by experienced endoscopists. In our hospital, our endoscopic center provides therapeutic endoscopic services 24 hours a day. The registered clinical variables were demographic data; clinical manifestations of bleeding; time to endoscopy; the use of tobacco, alcohol, aspirin, clopidogrel, and nonsteroidal anti-inflammatory drugs (NSAIDs); and comorbidities such as diabetes mellitus, cardiovascular disease, stroke, chronic kidney disease (CKD), and chronic obstructive pulmonary disease. Other clinical characteristics, such as age, sex, and hemodynamic instability on admission, and laboratory data, including hemoglobin, platelet count, and international normalized ratio, were analyzed. The endpoints were rebleeding, need for surgery, and mortality.

This retrospective chart review study was approved by both the Institutional Review Board and the Ethics Committee of Chang Gung Memorial Hospital, Taiwan (IRB1031639B). All patients were at least 18 years old and provided written informed consent before undergoing endoscopic interventions.

2.2. Definitions. The holidays were defined as all national holidays and weekends in Taiwan during the study period. Patients with peptic ulcer bleeding were treated with intravenous high-dose PPIs (pantoprazole or esomeprazole $80 \mathrm{mg}$ bolus followed by $200 \mathrm{mg}$ continuous infusion for 3 days). Rebleeding was defined as a new onset of hematemesis, melena, fresh blood or coffee ground material in the nasogastric (NG) tube, or both associated with tachycardia or hypovolemic shock or a decrease in serum hemoglobin level $>2 \mathrm{~g} / \mathrm{dL}$ after successful endoscopic and pharmacological treatment, and hemodynamic stability of at least a 24-hour period of stable vital signs [10-12]. Bleeding recurrence was confirmed by endoscopy in all cases. Shock was defined as tachycardia, heart rate $\geq 100 / \mathrm{min}$, or hypotension (systemic blood pressure $\leq 90 \mathrm{mmHg}$ ) [13-16].

2.3. Endoscopic Assessment. Endoscopic signs of high-risk ulcers were defined according to the Forrest classification [16]. In high-risk stigmata, active bleeding was defined as continuous blood spurting (Forrest IA) or oozing (Forrest IB) from the ulcer base. A nonbleeding vessel visible at endoscopy was defined as a discrete protuberance at the ulcer base (Forrest IIA). An adherent clot was resistant to forceful irrigation or suction (Forrest IIB). In low-risk stigmata, flat, pigmented spots or clean bases were defined as Forrest grade IIC or III. We performed endoscopic hemostasis for all patients with peptic ulcers and high-risk stigmata.

2.4. Statistical Analysis. The Statistical Package for Social Sciences (SPSS22.0 for Windows, IBM Corp., Armonk, NY, USA) was used to analyze the data. The results are expressed as distributions, absolute frequencies, relative frequencies, medians and ranges, or mean \pm SD. The quantitative data were compared using Student's $t$-test for normally distributed variables. Differences between the proportions of categorical data were evaluated with the $\chi^{2}$ test or with Fisher's exact test when the number of expected subjects was less than five. Differences were considered statistically significant at $P<$ 0.05 .

\section{Results}

3.1. Demographic and Clinical Characteristics. The patients' demographics and clinical characteristics are shown in Table 1. There were no significant differences between the two groups.

3.2. Rebleeding and Receipt of Red Cell Transfusion. Univariate analysis revealed that the percentages of patients who experienced rebleeding were comparable between the nonholiday and holiday groups (23.4\% versus $17.8 \%, P=$ 0.167 ; Table 2$)$. The holiday group required smaller amounts of transfused blood ( $4.8 \pm 5.2$ units versus $6.6 \pm 9.3$ units, $P=0.02$; Figure 2).

3.3. Time to Endoscopy, Length of Hospital Stay, and Time to Oral PPI. We found that patients in the holiday group received earlier endoscopy treatment $(12.2 \pm 15.3 \mathrm{~h}$ versus $16.7 \pm 19.8 \mathrm{~h}, P=0.008$; Table 2 ). In addition, patients in the nonholiday group required longer hospital stays than the holiday group $(17.4 \pm 28.2$ days versus $12.1 \pm 12.5$ days, $P=$ $0.005)$ and required more time to shift from intravenous to oral PPI (6.9 \pm 9.1 days versus 5.3 \pm 6.1 days, $P=0.05$; Table 2$)$.

3.4. Surgical Intervention and Mortality. There was no significant difference in the number of patients who required surgeries between the two groups, but a trend toward significance was observed for the nonholiday group patients and higher rate of surgical intervention $(2.1 \%$ versus $4.7 \%, P=0.093$; Figure 2). There was no significant difference in mortality 


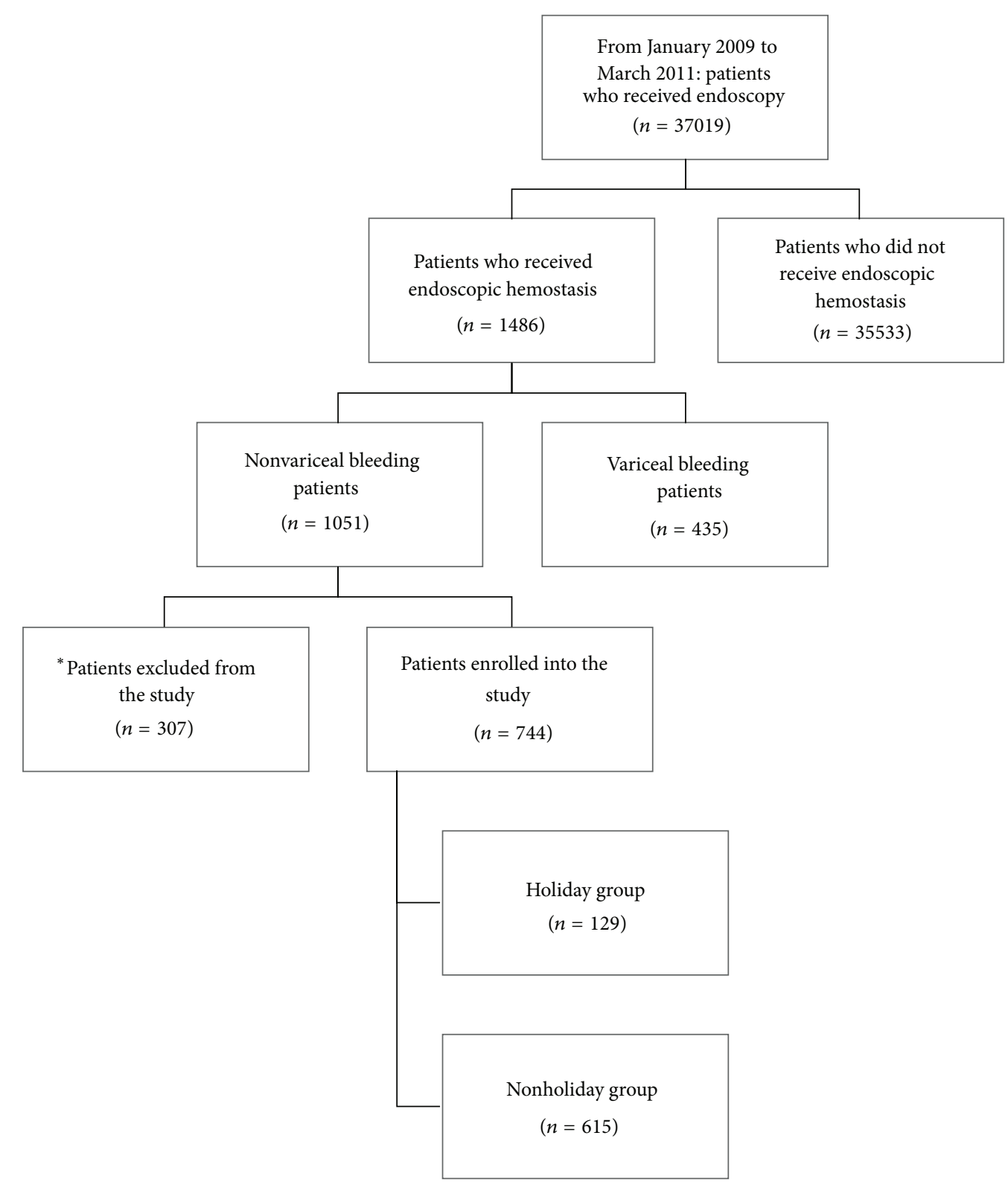

* Patients with malignant ulcers or nonulcerative bleeding, such as angiodysplasia, and

Mallory-Weiss tear, and subjects who were lost to follow-up before 30 days except

mortality and incomplete medical records

FIGURE 1: Schematic flowchart of the study design and the patient numbers during follow-up.

between the two groups $(13.66 \%$ versus $11.63 \%, P=0.537$; Figure 2).

\section{Discussion}

A growing body of health services research indicates that increased mortality is associated with admission to hospitals on the weekends [17-20]. This issue has raised concern over the quality care of very important medical and surgical emergencies, including peptic ulcer bleeding, on holidays.
The existing reports reached inconsistent results. Some studies describe increased rates of adverse outcomes [3, 4, 21], whereas some reported that there is no evidence of a "holiday effect" $[5,6,22]$. The present study suggests that the holiday effect was not observed for patients with peptic ulcer bleeding who were treated in our hospital. The percentages of patients who suffered from rebleeding and mortality and those who needed surgery were comparable between the nonholiday and holiday patients. In fact, the holiday group required less transfused blood, had a shorter time to endoscopy, more 
TABLE 1: Baseline characteristics of nonholiday and holiday groups.

\begin{tabular}{|c|c|c|c|}
\hline Characteristics & Nonholiday group $(n=615)$ & Holiday group $(n=129)$ & $P$ value \\
\hline Age (yr) & $64.6 \pm 14.1$ & $66.45 \pm 14.1$ & 0.978 \\
\hline Female gender, $n(\%)$ & $195(32 \%)$ & $48(37 \%)$ & 0.226 \\
\hline $\mathrm{Hb}(\mathrm{g} / \mathrm{dL})$ & $9.3 \pm 2.8$ & $9.2 \pm 2.7$ & 0.848 \\
\hline Platelets $\left(\times 10^{3} / \mu \mathrm{L}\right)$ & $190.1 \pm 99.3$ & $205.4 \pm 120.1$ & 0.244 \\
\hline INR & $1.24 \pm 0.64$ & $1.17 \pm 0.49$ & 0.116 \\
\hline Use of NSAIDs, $n(\%)$ & $72(12 \%)$ & $9(7 \%)$ & 0.117 \\
\hline Use of aspirin, $n(\%)$ & $93(15 \%)$ & $18(14 \%)$ & 0.735 \\
\hline Use of clopidogrel, $n(\%)$ & $65(11 \%)$ & $14(11 \%)$ & 0.924 \\
\hline Use of warfarin, $n(\%)$ & $32(5 \%)$ & $5(4 \%)$ & 0.528 \\
\hline Shock at presentation & $311(51 \%)$ & $76(59 \%)$ & 0.084 \\
\hline \multicolumn{4}{|l|}{ Coexisting illness, $n(\%)$} \\
\hline CKD III, IV/V & $204 / 83(33 \% / 13 \%)$ & $49 / 11(40 \% / 9 \%)$ & 0.245 \\
\hline COPD & $44(7 \%)$ & $11(9 \%)$ & 0.588 \\
\hline CAD & $110(18 \%)$ & $19(15 \%)$ & 0.389 \\
\hline $\mathrm{DM}$ & $199(32 \%)$ & $36(28 \%)$ & 0.323 \\
\hline CVA & $105(17 \%)$ & $24(19 \%)$ & 0.676 \\
\hline HTN & $326(53 \%)$ & $63(49 \%)$ & 0.389 \\
\hline Cancer & $116(19 \%)$ & $24(19 \%)$ & 0.946 \\
\hline Liver cirrhosis & $115(19 \%)$ & $20(16 \%)$ & 0.392 \\
\hline Rockall score & $6.2 \pm 1.7$ & $6.0 \pm 1.8$ & 0.727 \\
\hline Ulcer size $(\mathrm{cm})$ & $1.1 \pm 0.7$ & $1.2 \pm 0.8$ & 0.434 \\
\hline \multicolumn{4}{|l|}{ Forrest classification } \\
\hline Ia/Ib/IIa/IIb/IIc/III & $44 / 348 / 67 / 140 / 14 / 2$ & $8 / 62 / 20 / 33 / 6 / 0$ & 0.260 \\
\hline High stigmata, $n(\%)$ & $599(97.3 \%)$ & $123(95.3 \%)$ & 0.212 \\
\hline
\end{tabular}

Hb: hemoglobin; NSAIDs: nonsteroidal anti-inflammatory drugs; CKD: chronic kidney disease; COPD: chronic obstructive pulmonary disease; CAD: coronary artery disease; DM: diabetes mellitus; CVA: cerebral vascular accident; INR: international normalized ratio HTN: hypertension.

TABLE 2: Clinical outcomes for all patients presenting with acute upper gastrointestinal bleeding.

\begin{tabular}{lccc}
\hline Characteristics & Nonholiday group $(n=615)$ & Holiday group $(n=129)$ & $P$ value \\
\hline Time to oral PPI (days) & $6.9 \pm 9.1$ & $5.3 \pm 6.1$ & $0.05^{*}$ \\
Rebleeding, $n(\%)$ & $144(23.4 \%)$ & $23(17.8 \%)$ & $6(4.7 \%)$ \\
Surgery, $n(\%)$ & $13(2.1 \%)$ & $12.1 \pm 12.5$ & 0.167 \\
Hospital stay (days) & $17.4 \pm 28.2$ & $15(11.6 \%)$ & 0.097 \\
Mortality, $n$ (\%) & $84(13.7 \%)$ & $5(3.9 \%) / 10(7.7 \%)$ & $0.005^{*}$ \\
Bleeding related/other causes & $24(3.9 \%) / 60(9.8 \%)$ & $12.2 \pm 15.3$ & 0.776 \\
Time to endoscopy (h) & $16.7 \pm 19.8$ & $4.8 \pm 5.2$ & $0.008^{*}$ \\
PRBC BT (U) & $6.6 \pm 9.3$ & & $0.020^{*}$ \\
\hline
\end{tabular}

${ }^{*}$ A significant value.

PRBC BT: blood transfusion of packed red blood cell; PPI: proton pump inhibitor.

quickly shifted from intravenous to oral PPI, and had shorter hospital stays.

Generally, the outcome of treatment for peptic ulcer bleeding should be much improved given the emergence of more potent medications such as PPIs, increased use of dual endoscopic therapy and endoscopic triage for risk stratification, and advances in general medical care. Shaheen et al. observed an overall $25 \%$ reduction in the odds of mortality, irrespective of the day of admission, when comparing the 2000-2005 and 1993-1999 time periods [21]. However, patients admitted to hospital on the weekend for peptic ulcerrelated hemorrhage have a higher mortality rate and more frequently undergo surgery [4]. For those reports suggesting a weekend or holiday effect of peptic ulcer bleeding, the explanations included lower staffing levels, less senior staff, cross-cover of clinical specialties, and a lower likelihood that invasive procedures, such as endoscopy, will be undertaken on weekends $[4,21]$. Early endoscopic interventions and the first 72 hours of hospitalization are crucial for favorable outcomes in patients with peptic ulcer bleeding, especially 


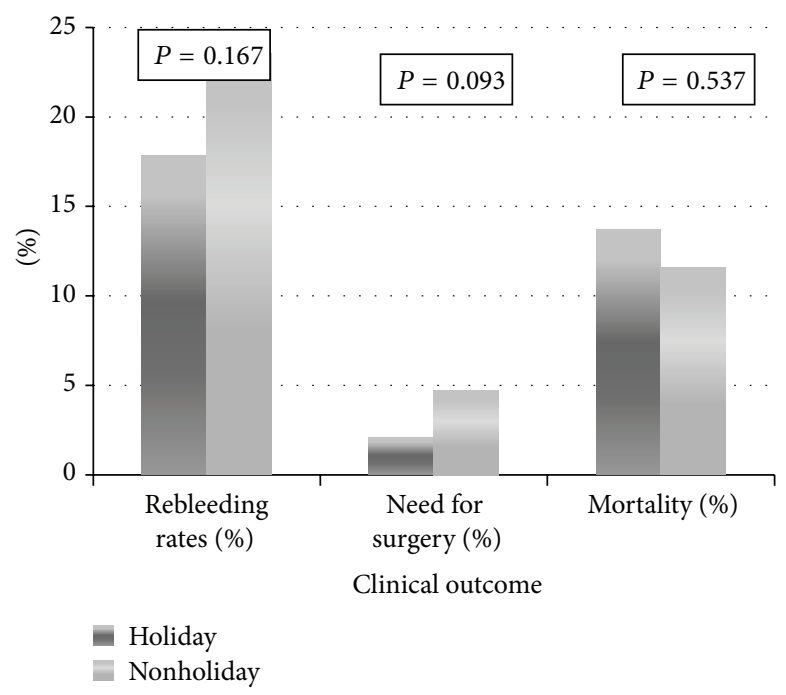

FIGURE 2: The clinical outcomes of holiday and nonholiday patients.

the rebleeding rates. Therefore, the availability of early access to upper endoscopy and physicians with endoscopic expertise are key factors to treatment success [23-25]. A lack of staff on holidays and subsequent delays in upper endoscopy may explain the poorer outcomes. However, Ananthakrishnan et al. observed that the difference in mortality for weekend admissions was only significant among patients who did not undergo endoscopic intervention, with similar outcomes among the groups that did undergo emergency endoscopy [4]. Large population-based reports from the US, Canada, and the Netherlands describe the rates of early endoscopy as $72 \%, 76 \%$, and $78 \%$, respectively [26-28], but these data were from older publications. Recently, Haas et al. reported that $>94 \%$ of patients with peptic ulcer bleeding undergo upper endoscopy within 24 hours. In the current study, $83.2 \%$ of patients with peptic ulcer bleeding underwent upper endoscopy within 24 hours.

Recent publications have suggested that the holiday effect did not influence the outcome of peptic ulcer bleeding $[6,22]$, which is in accordance with the present results. Those studies that did not find differences were probably performed in hospitals that were able to provide full-time therapeutic endoscopic services for early endoscopy. Therefore, the effects of lower staffing levels, less senior staff, and lower likelihood of invasive procedure on holidays were not problematic in these hospitals. Indeed, we found that patients in the holiday group received earlier endoscopy treatment than nonholiday patients $(12.2 \pm 15.3 \mathrm{~h}$ versus $16.7 \pm 19.8 \mathrm{~h}, P=0.008)$.

Nevertheless, previous studies also pointed out that patients presenting on weekends might be more critically ill than those presenting on weekdays. However, we observed that patients admitted with peptic ulcer bleeding on holidays and nonholidays were comparable for coexisting illness, shock status, and Rockall scores. Nahon et al. reported similar findings in a post hoc subanalysis of a prospective study performed in 53 general nonuniversity hospitals in France [22]. They further explained that the severity of bleeding estimated by the Rockall score and the rates of endoscopic interventions for active bleeding did not differ between weekend and weekday admissions. Importantly, a senior gastrointestinal specialist was on call and available on weekends in their hospitals. In addition, we had well-trained emergency room physicians who understood and adhered to the guidelines for early risk stratification in patients with peptic ulcer bleeding $[23,24]$.

In Taiwan, medical care is well covered by the National Health Insurance system. Patients are allowed to seek medical care in referral hospitals, including medical centers and university hospitals, regardless of the severity of their illness. For instance, patients with peptic ulcer bleeding are allowed to go to a hospital center with full-time therapeutic endoscopic services. In our endoscopic teams, a senior gastroenterology specialist who supervises the lower level staff members is always on call, even on holidays. This is necessary to minimize the difference of endoscopist skill and reduce waiting time, regardless of whether it is a holiday or nonholiday. This could also be one reason why the patients with peptic ulcer bleeding admitted on holidays achieved good outcomes in the present study.

This study was limited by the fact that it was a retrospective chart review study performed at a single institution, which could have resulted in sampling bias. In conclusion, patients who present with peptic ulcer bleeding on holidays did not experience delayed endoscopy or increased adverse outcomes, such as recurrent bleeding or mortality. In fact, patients who received endoscopic hemostasis on holidays experienced shorter waiting times, required less transfused blood, were more quickly shifted from intravenous to oral PPI, and had shorter hospital stays.

\section{Conflict of Interests}

The authors declare that there is no conflict of interests regarding the publication of this paper. 


\section{References}

[1] O. Blatchford, L. A. Davidson, W. R. Murray, M. Blatchford, and J. Pell, "Acute upper gastrointestinal haemorrhage in west of Scotland: case ascertainment study," British Medical Journal, vol. 315, no. 7107, pp. 510-514, 1997.

[2] G. C. Jiranek and R. A. Kozarek, "A cost-effective approach to the patient with peptic ulcer bleeding," Surgical Clinics of North America, vol. 76, no. 1, pp. 83-103, 1996.

[3] S. D. Dorn, N. D. Shah, B. P. Berg, and J. M. Naessens, "Effect of weekend hospital admission on gastrointestinal hemorrhage outcomes," Digestive Diseases and Sciences, vol. 55, no. 6, pp. 1658-1666, 2010.

[4] A. N. Ananthakrishnan, E. L. McGinley, and K. Saeian, "Outcomes of weekend admissions for upper gastrointestinal hemorrhage: a nationwide analysis," Clinical Gastroenterology and Hepatology, vol. 7, no. 3, pp. 296-302, 2009.

[5] J. M. Haas, J. D. Gundrum, and S. W. Rathgaber, "Comparison of time to endoscopy and outcome between weekend/weekday hospital admissions in patients with upper GI hemorrhage," Wisconsin Medical Journal, vol. 111, no. 4, pp. 161-165, 2012.

[6] V. Jairath, B. C. Kahan, R. F. A. Logan et al., "Mortality from acute upper gastrointestinal bleeding in the United Kingdom: does it display a "weekend effect"?", The American Journal of Gastroenterology, vol. 106, no. 9, pp. 1621-1628, 2011.

[7] H.-.J. Lin, K. Wang, C.-.L. Perng, R.-T. Chua, C.-H. Lee, and S.-D. Lee, "Octreotide and heater probe thermocoagulation for arrest of peptic ulcer hemorrhage: a prospective, randomized, controlled trial," Journal of Clinical Gastroenterology, vol. 21, no. 2, pp. 95-98, 1995.

[8] L. Laine, "Multipolar electrocoagulation versus injection therapy in the treatment of bleeding peptic ulcers: a prospective, randomized trial," Gastroenterology, vol. 99, no. 5, pp. 13031306, 1990.

[9] T. A. Rockall, R. F. A. Logan, H. B. Devlin, and T. C. Northfield, "Risk assessment after acute upper gastrointestinal haemorrhage," Gut, vol. 38, no. 3, pp. 316-321, 1996.

[10] H. W. Xu, J. H. Wang, M. S. Tsai et al., "The effects of cefazolin on cirrhotic patients with acute variceal hemorrhage after endoscopic interventions," Surgical Endoscopy and Other Interventional Techniques, vol. 25, no. 9, pp. 2911-2918, 2011.

[11] S. C. Lin, K. L. Wu, K. W. Chiu et al., "Risk factors influencing the outcome of peptic ulcer bleeding in end stage renal diseases after initial endoscopic haemostasis," International Journal of Clinical Practice, vol. 66, no. 8, pp. 774-781, 2012.

[12] C. K. Wu, J. H. Wang, C. H. Lee et al., "The outcome of prophylactic intravenous cefazolin and ceftriaxone in cirrhotic patients at different clinical stages of disease after endoscopic interventions for acute variceal hemorrhage," PLoS ONE, vol. 8, no. 4, Article ID e61666, 2013.

[13] C. M. Liang, J. H. Lee, Y. H. Kuo et al., "Intravenous non-highdose pantoprazole is equally effective as high-dose pantoprazole in preventing rebleeding among low risk patients with a bleeding peptic ulcer after initial endoscopic hemostasis," $B M C$ Gastroenterology, vol. 12, article 28, 2012.

[14] L. S. Lu, S. C. Lin, C. M. Kuo et al., "A real world report on intravenous high-dose and non-high-dose proton-pump inhibitors therapy in patients with endoscopically treated high-risk peptic ulcer bleeding," Gastroenterology Research and Practice, vol. 2012, Article ID 858612, 7 pages, 2012.

[15] S. C. Yang, K. L. Wu, J. H. Wang et al., "The effect of systemic antibiotic prophylaxis for cirrhotic patients with peptic ulcer bleeding after endoscopic interventions," Hepatology International, vol. 7, no. 1, pp. 257-267, 2013.

[16] J. A. H. Forrest, N. D. C. Finlayson, and D. J. C. Shearman, "Endoscopy in gastrointestinal bleeding," The Lancet, vol. 2, no. 7877, pp. 394-397, 1974.

[17] C. M. Bell and D. A. Redelmeier, "Mortality among patients admitted to hospitals on weekends as compared with weekdays," The New England Journal of Medicine, vol. 345, no. 9, pp. 663668, 2001.

[18] P. Cram, S. L. Hillis, M. Barnett, and G. E. Rosenthal, "Effects of weekend admission and hospital teaching status on in-hospital mortality," The American Journal of Medicine, vol. 117, no. 3, pp. 151-157, 2004.

[19] D. J. Becker, "Do hospitals provide lower quality care on weekends?" Health Services Research, vol. 42, no. 4, pp. 1589$1612,2007$.

[20] M. J. Barnett, P. J. Kaboli, C. A. Sirio, and G. E. Rosenthal, "Day of the week of intensive care admission and patient outcomes: a multisite regional evaluation," Medical Care, vol. 40, no. 6, pp. 530-539, 2002.

[21] A. A. M. Shaheen, G. G. Kaplan, and R. P. Myers, "Weekend versus weekday admission and mortality from gastrointestinal hemorrhage caused bypeptic ulcer disease," Clinical Gastroenterology and Hepatology, vol. 7, no. 3, pp. 303-310, 2009.

[22] S. Nahon, O. Nouel, H. Hagège et al., "Favorable prognosis of uppergastrointestinal bleeding in 1041 older patients: results of a prospective multicenter study," Clinical Gastroenterology and Hepatology, vol. 6, no. 8, pp. 886-892, 2008.

[23] D. G. Adler, J. A. Leighton, R. E. Davila et al., "ASGE guideline: the role of endoscopy in acute non-variceal upper-GI hemorrhage," Gastrointestinal Endoscopy, vol. 60, no. 4, pp. 497-504, 2004.

[24] A. N. Barkun, M. Bardou, E. J. Kuipers et al., "International consensus recommendations on the management of patients with nonvariceal upper gastrointestinal bleeding," Annals of Internal Medicine, vol. 152, no. 2, pp. 101-113, 2010.

[25] J. J. Y. Sung, F. K. L. Chan, M. Chen, and C. Y. Wu, "Asia-Pacific Working Group consensus on non-variceal upper gastrointestinal bleeding," Gut, vol. 60, no. 10, pp. 1170-1177, 2011.

[26] G. S. Cooper, T. D. Kou, and R. C. K. Wong, "Use and impact of early endoscopy in elderly patients with peptic ulcer hemorrhage: a population-based analysis," Gastrointestinal Endoscopy, vol. 70, no. 2, pp. 229-235, 2009.

[27] A. Barkun, S. Sabbah, R. Enns et al., "The Canadian Registry on Nonvariceal Upper Gastrointestinal Bleeding and Endoscopy (RUGBE): endoscopic hemostasis and proton pump inhibition are associated with improved outcomes in a real-life setting," The American Journal of Gastroenterology, vol. 99, no. 7, pp. 1238-1246, 2004.

[28] E. M. Vreeburg, P. Snel, J. W. de Bruijne, J. F. W. M. Bartelsman, E. A. J. Rauws, and G. N. J. Tytgat, "Acute upper gastrointestinal bleeding in the Amsterdam area: incidence, diagnosis, and clinical outcome," The American Journal of Gastroenterology, vol. 92, no. 2, pp. 236-243, 1997. 


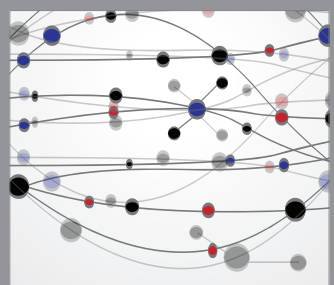

The Scientific World Journal
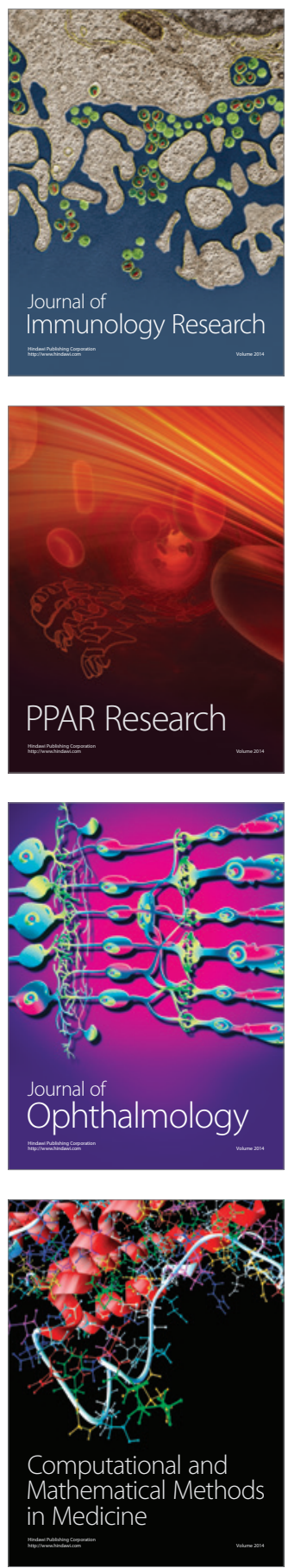

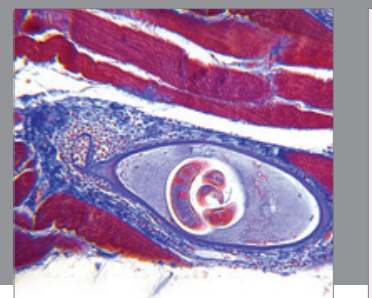

Gastroenterology

Research and Practice
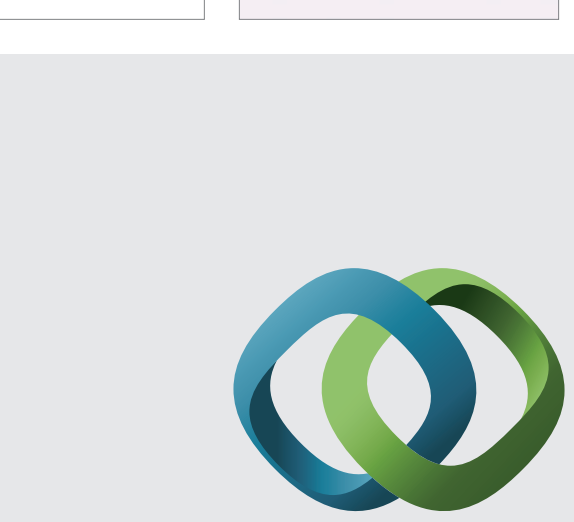

\section{Hindawi}

Submit your manuscripts at

http://www.hindawi.com
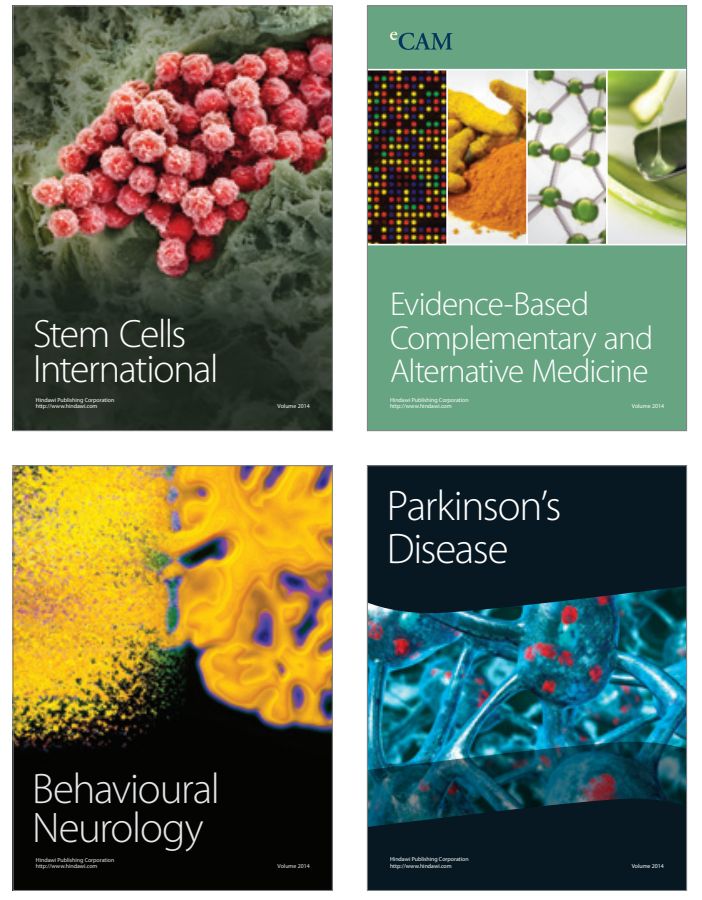
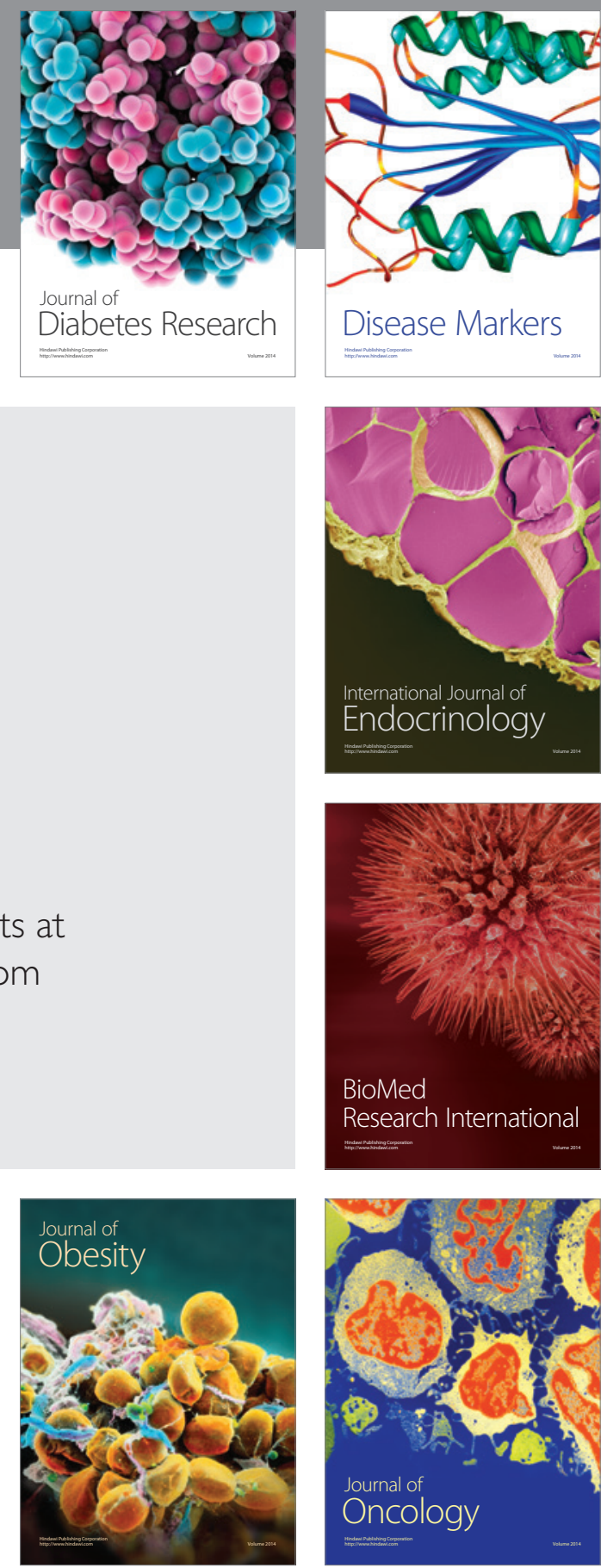

Disease Markers
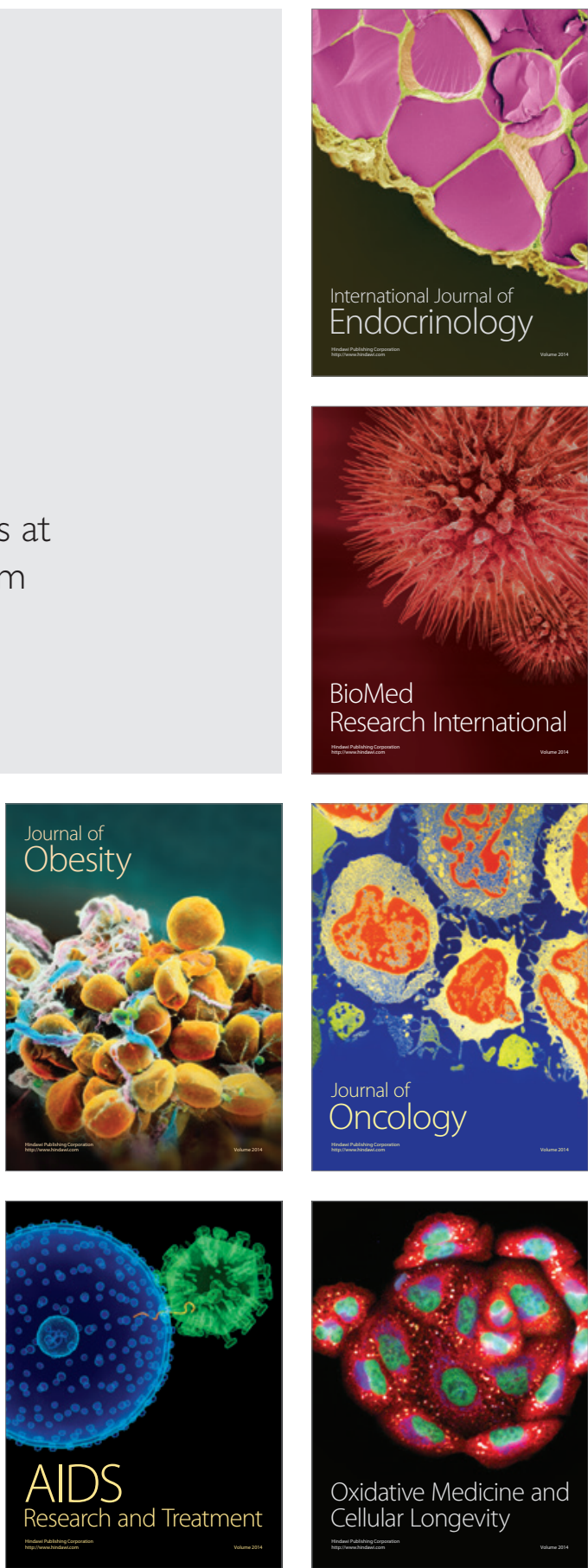